\title{
An Elementary Group Contribution Model for Normal Alkane Mixtures
}

\author{
Constantinos G. PANAYIOTOU \\ Chemical Process Engineering Research Institute, and Department \\ of Chemical Engineering, University of Thessaloniki, \\ 54006 Thessaloniki, Greece
}

(Received March 10, 1988)

\begin{abstract}
The Lattice-Fluid (LF) theory of $r$-mer mixtures, as modified recently by the author, is reformulated in terms of contributions of functional groups. The model is applied to the homologous series of $n$-alkanes and their mixtures which can be represented by appropriate combinations of only two groups: $-\mathrm{CH}_{3}$ and $-\mathrm{CH}_{2}-$. A single set of scaling constants for each of these groups has been used for all the investigated properties at all external conditions. The development is in conformity with the principle of congruence. The performance of the model is satisfactory. Comparison with the corresponding formulation of Flory's equation-of-state theory is, also, discussed.

KEY WORDS Thermodynamics / Group Contribution / Paraffin Liquids /

Oligomers / Lattice-Fluid Theory / Polymer Solutions /
\end{abstract}

Group contribution methods have been proved the most prominent tools in chemical thermodynamics for the prediction of the thermophysical behavior of complex systems. Their value lies in the relatively small number of parameters needed for the description of a large diversity of systems. For instance, all normal alkanes and alkanols and all mixtures thereof may be conceived as consisting of appropriate combinations of only three groups, namely, $-\mathrm{CH}_{2}-,-\mathrm{CH}_{3}$, and $-\mathrm{OH}$. Thus, instead of seeking the determination of the model parameters of all pure components and the multicomponent parameters of all conceivable combinations of mixtures, one has to evaluate in the previous example the model parameters for, only, the three groups and their interaction parameters.

In the thermodynamics of polymer mixtures, group contribution methods play a particularly important role since they may form the basis for consistent treatments of copolymer mixtures ${ }^{1}$ and chain-end effects in oligo- mers and high polymers.

In a series of recent papers $^{2-4}$ we have presented a modified Lattice-Fluid (LF) theory of r-mer mixtures and discussed its advantages over, both, the original theory of Sanchez and Lacombe ${ }^{5}$ and the equation-ofstate theory of Flory and his collaborators. ${ }^{6-8}$ In this work we are reformulating the LF theory in terms of contributions of functional groups. In this formulation we are centering our attention to the number and the type of the present groups regardless of the type of molecules they belong to. In order to test the validity of this approach we have chosen as model systems the homologous normal paraffins and their mixtures. The effects of the characteristic properties of the component liquids on the properties of their mixtures are nowhere more clearly manifest than in these mixtures. It is shown that group contributions may easily account for the negative volumes and the positive enthalpies of mixing in these mixtures and their variation with temperature. 


\section{THEORY}

The formalism of the group-contribution approach is equally valid to pure components and to mixtures. We will, then, present directly the case of mixtures. Let in our system be $\mathrm{K}$ kinds of groups, belonging to $\mathrm{z}$ types of molecules. As in the molecular version of the Lattice-Fluid theory ${ }^{3}$ each group of type $\mathrm{L}$ is characterized by three equation-of-state parameters, namely, a characteristic temperature $T_{\mathrm{L}}^{*}$, a characteristic pressure $P_{\mathrm{L}}^{*}$ and a characteristic density $\rho_{\mathrm{L}}^{*}$. An equivalent set of scaling constants is a number of segments per group, $r_{\mathrm{L}}$, a segmental close packed volume, $v_{\mathrm{L}^{\prime}}^{*}$ and a characteristic interaction energy, $\varepsilon_{L}$, for an external contact between two groups of type $L$. If $M_{\mathrm{L}}$ is the molar mass of the group L and $S_{\mathrm{L}}$ the average number of external contacts per segment, the following relations between the scaling constants hold:

$$
\begin{gathered}
v_{\mathrm{L}}^{*}=\frac{M_{\mathrm{L}}}{r_{\mathrm{L}} \rho_{\mathrm{L}}^{*}} \\
\varepsilon_{\mathrm{L}}^{*}=\frac{S_{\mathrm{L}}}{2} \varepsilon_{\mathrm{L}}=P_{\mathrm{L}}^{*} v_{\mathrm{L}}^{*}=k T_{\mathrm{L}}^{*}
\end{gathered}
$$

where $k$ is Boltzmann's constant.

Let $v_{\mathrm{Lt}}$ be the number of groups of type $\mathrm{L}$ in the molecule of type $t$. The total number of segments in the molecule $t$ is

$$
r^{(t)}=\sum_{\mathrm{L}} v_{\mathrm{LL}} r_{\mathrm{L}}
$$

while the total number of external contacts per molecule is

$$
r^{(t)} S^{(t)}=\sum_{\mathrm{L}} v_{\mathrm{Lt}} r_{\mathrm{L}} S_{\mathrm{L}}
$$

The segment fraction of group $\mathrm{L}$ in pure compound (molecule) $t$ is

$$
\Phi_{\mathrm{L}}^{(\mathrm{t})}=\frac{v_{\mathrm{LL}} r_{\mathrm{L}}}{r^{(\mathrm{t})}}
$$

The surface fraction of group $\mathrm{L}$ in pure molecule $t$ is

$$
\Theta_{\mathrm{L}}^{(\mathrm{t})}=\frac{v_{\mathrm{Lt}} r_{\mathrm{L}} S_{\mathrm{L}}}{r^{(\mathrm{t})} S^{(\mathrm{t})}}
$$

Let $N$ be the total number of molecules in our system, or

$$
N=N_{1}+N_{2}+\cdots+N_{\mathrm{t}}+\cdots+N_{\mathrm{z}}
$$

$N_{\mathrm{t}}$ being the number of molecules of type t. Molar segment fractions and surface fractions of component $t$ in the mixture are defined as following

$$
\begin{gathered}
\varphi_{\mathrm{t}}=\frac{N_{\mathrm{t}} r^{(\mathrm{t})}}{\sum_{\mathrm{i}} N_{\mathrm{i}} r^{(\mathrm{i})}}=\frac{N_{\mathrm{t}} r^{(\mathrm{t})}}{r N} \\
\vartheta_{\mathrm{t}}=\frac{N_{\mathrm{t}} r^{(\mathrm{t})} S^{(\mathrm{t})}}{\sum_{\mathrm{i}} N_{\mathrm{i}} r^{(\mathrm{i})} S^{(\mathrm{i})}}=\frac{N_{\mathrm{t}} r^{(\mathrm{t})} S^{(\mathrm{t})}}{r S N}
\end{gathered}
$$

On the basis of these definitions, the overall segment fraction of group L in our multicomponent-multigroup system is given by

$$
\Phi_{\mathrm{L}}=\sum_{\mathrm{t}} \varphi_{\mathrm{t}} \Phi_{\mathrm{L}}^{(\mathrm{t})}
$$

while the overall surface fraction of group $L$ in the system is

$$
\Theta_{L}=\sum_{t} \vartheta_{t} \Theta_{L}^{(t)}
$$

In the one-fluid approach an average closepacked volume per segment, $v^{*}$, in our system is obtained from the classical quadratic mixing rule

$$
v^{*}=\sum_{\mathbf{L}} \Phi_{\mathrm{L}}^{2} v_{\mathrm{L}}^{*}+2 \sum_{\mathbf{L}} \sum_{\mathbf{M}>\mathbf{L}} \Phi_{\mathrm{L}} \Phi_{\mathbf{M}} v_{\mathrm{LM}}^{*}
$$

Following our previous work ${ }^{2,3}$ the following combining rule will be used for $v_{\mathrm{LM}}^{*}$

$$
v_{\mathrm{LM}}^{*}=\xi_{\mathrm{LM}}\left(\frac{v_{\mathrm{L}}^{* 1 / 3}+v_{\mathrm{M}}^{* 1 / 3}}{2}\right)^{3}
$$

$\xi_{\text {LM }}$ being binary adjustable correction parameter expected to have values close to unity.

To complete the set of the scaling constants for the mixture we need its characteristic interaction energy, $\varepsilon^{*}$, which is given by 


$$
\varepsilon^{*}=\sum_{\mathrm{L}} \Phi_{\mathrm{L}} \varepsilon_{\mathrm{L}}^{*}-\sum_{\mathrm{L}} \sum_{\mathrm{M}>\mathrm{L}} \Phi_{\mathrm{L}} \Theta_{\mathrm{M}} k T X_{\mathrm{LM}}
$$

where

$$
X_{\mathrm{LM}}=\frac{\varepsilon_{\mathrm{L}}^{*}+\frac{S_{\mathrm{L}}}{S_{\mathrm{M}}} \varepsilon_{\mathrm{M}}^{*}-2 \sqrt{\frac{S_{\mathrm{L}}}{S_{\mathrm{M}}}} \varepsilon_{\mathrm{LM}}^{*}}{k T}
$$

$T$ being the absolute temperature of the system.

Berthelot's rule is used for the evaluation of the binary interaction energy $\varepsilon_{\mathrm{LM}}^{*}$

$$
\varepsilon_{\mathrm{LM}}^{*}=\zeta_{\mathrm{LM}} \sqrt{\varepsilon_{\mathrm{L}}^{*} \varepsilon_{\mathrm{M}}^{*}}
$$

$\zeta_{\text {LM }}$ being a binary adjustable correction parameter expected to have values close to unity.

In direct analogy to eq 2 we obtain for the characteristic temperature and pressure of the system

$$
T^{*}=\frac{\varepsilon^{*}}{k}, \quad P^{*}=\frac{\varepsilon^{*}}{v^{*}}
$$

These parameters may be used to scale the temperature $T$ and pressure $P$ of the system giving for the corresponding reduced quantities

$$
\tilde{T}=\frac{T}{T^{*}}, \quad \tilde{P}=\frac{P}{P^{*}}
$$

The total volume of the system is given by

$$
V=r N v^{*} \tilde{v}
$$

The reduced volume $\tilde{v}$ may be obtained from the equation of state which, according to the Lattice-Fluid theory, ${ }^{3,5}$ may be written as

$$
\tilde{P}+\tilde{\rho}^{2}+\tilde{T}\left[\ln (1-\tilde{\rho})+\left(1-\frac{1}{r}\right) \tilde{\rho}\right]=0
$$

$\tilde{\rho}$ being the reduced density $(\tilde{\rho}=1 / \tilde{v})$. The excess volume is, then, given by

$$
\begin{aligned}
V^{E} & =V-\sum_{t} r^{(t)} N_{t} v^{*(t)} \tilde{v}^{(t)} \\
& =r N\left[v^{*} \tilde{v}-\sum_{t} \varphi_{t} v^{*(t)} \tilde{v}^{(t)}\right]
\end{aligned}
$$

The potential energy of the system is given by

$$
-E=\frac{r N \varepsilon^{*}}{\tilde{v}}
$$

and the excess enthalpy by

$$
\begin{aligned}
H^{E} & =E+P V-\sum_{\mathrm{t}}\left(E^{(\mathrm{t})}+P V^{(\mathrm{t})}\right) \\
& =r N\left(\sum_{\mathrm{t}} \varphi_{\mathrm{t}} \tilde{\rho}^{(\mathrm{t})} \varepsilon_{\mathrm{i}}^{*(\mathrm{t})}-\tilde{\rho} \varepsilon^{*}\right)+P V^{E}
\end{aligned}
$$

All quantities with superscript $t$ in eq 21 and 23 refer, of course, to molecules of type $t$. Application, for instance, of eq 14 to pure component $\mathrm{t}$ gives for $\varepsilon^{*(t)}$

$$
\varepsilon^{*(\mathrm{t})}=\sum_{\mathrm{L}} \Phi_{\mathrm{L}}^{(\mathrm{t})} \varepsilon_{\mathrm{L}}^{*}=\sum_{\mathrm{L}} \sum_{\mathrm{M}>\mathrm{L}} \Phi_{\mathrm{L}}^{(\mathrm{t})} \Theta_{\mathrm{M}}^{(\mathrm{t})} k T X_{\mathrm{LM}}
$$

\section{APPLICATIONS}

As pointed out earlier, the most appropriate class of systems for testing the above model are the homologous series of normal alkanes and their mixtures. The molar excess volume, $V^{\mathrm{E}}$, for these mixtures is negative and its magnitude increases rapidly with temperature. The molar excess enthalpy, $H^{\mathrm{E}}$, is positive at ordinary temperature but decreases markedly with temperature becoming negative at sufficiently elevated temperatures.

Description of the homologous series of normal paraffins can be made by considering contributions of only two groups: $-\mathrm{CH}_{3}$ and $-\mathrm{CH}_{2}-$. The parameters needed, then, are: three scaling constants for each of the two groups, the binary adjustable parameters $\xi$ and $\zeta$ of eq 13 and 16 and the "molecular" binary parameter $S_{\mathrm{CH}_{3}} / S_{\mathrm{CH}_{2}}$. For simplicity, the following steps have been taken in this work for the specification of the above parameters.

High polyethylene has been considered as consisting of only $-\mathrm{CH}_{2}-$ groups and, thus, the LF parameters for $-\mathrm{CH}_{2}-$ have been obtained from the literature values of the corresponding parameters for polyethylene. ${ }^{5}$ Since the majority of systems of interest in this work are at much lower denisities than the high density 


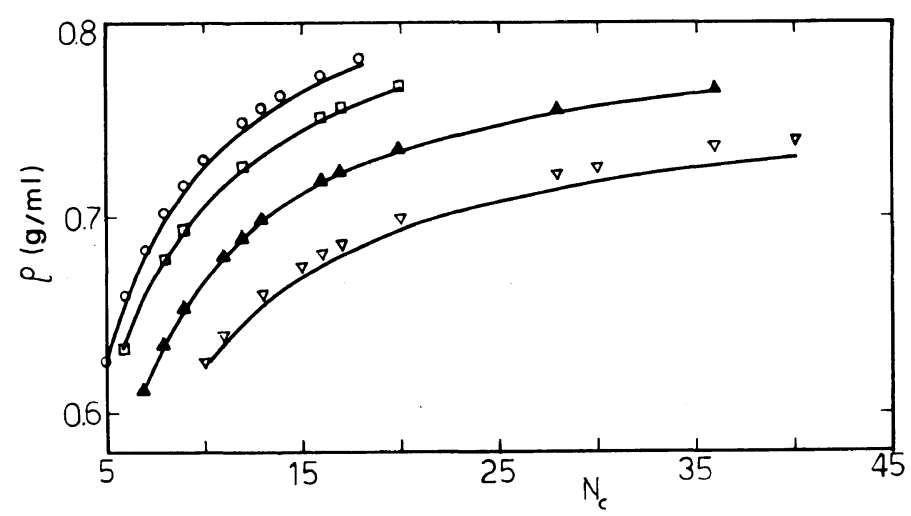

Figure 1. Experimental $l^{6,7}$ and calculated densities of normal paraffin liquids $v s$. the number of carbon atoms. $\bigcirc, 20^{\circ} \mathrm{C} ; \square, 50^{\circ} \mathrm{C} ; \Delta, 100^{\circ} \mathrm{C} ; \nabla, 150^{\circ} \mathrm{C}$.

polyethylene and with some degree of arbitrariness we have taken as characteristic scaling constants for the $-\mathrm{CH}_{2}-$ group the arithmetic mean of the corresponding constants for the HDPE and the LDPE, ${ }^{5}$ or, $T_{\mathrm{CH}_{2}}^{*}=661 \mathrm{~K}$, $v_{\mathrm{CH}_{2}}^{*}=14.15 \mathrm{~cm}^{3} \mathrm{~mol}^{-1}, r_{\mathrm{CH}_{2}}=1.118$. No further adjustment of these parameters has been made throughout.

Both binary parameters, $\xi$ and $\zeta$, have been taken equal to unity.

The scaling constants for $-\mathrm{CH}_{3}$ have been obtained from reduction of experimental data on densities of $n$-alkanes from $\mathrm{C}_{5}$ to $\mathrm{C}_{40}$ and from $20^{\circ} \mathrm{C}$ to $150^{\circ} \mathrm{C}$. Various sets of LF constants reproduce equally well these experimental data. In addition there is no unambiguous procedure for the evaluation of the ratio $S_{\mathrm{CH}_{2}} /$ $S_{\mathrm{CH}_{3} \cdot{ }^{6-8}}$ Fine adjustments of it and concomitant adjustments of the LF constants for the $-\mathrm{CH}_{3}$ group have been made in such a way that the excess enthalpy of the equimolar mixture of $n$-Hexane $+n$-Hexadecane between $30^{\circ} \mathrm{C}$ and $40^{\circ} \mathrm{C}$ be correctly estimated. No other mixture data have been used for the estimation of these parameters. The values thus obtained are: $T_{\mathrm{CH}_{3}}^{*}=401 \mathrm{~K}, \quad v_{\mathrm{CH}_{3}}^{*}=$ $13.40 \mathrm{~cm}^{3} \mathrm{~mol}^{-1}, r_{\mathrm{CH}_{3}}=1.951$ and $S_{\mathrm{CH}_{2}} / S_{\mathrm{CH}_{3}}=$ 0.62 .

In Figure 1 are shown experimental and calculated densities for normal paraffin liquids from $20^{\circ} \mathrm{C}$ to $150^{\circ} \mathrm{C}$. Calculated values are the

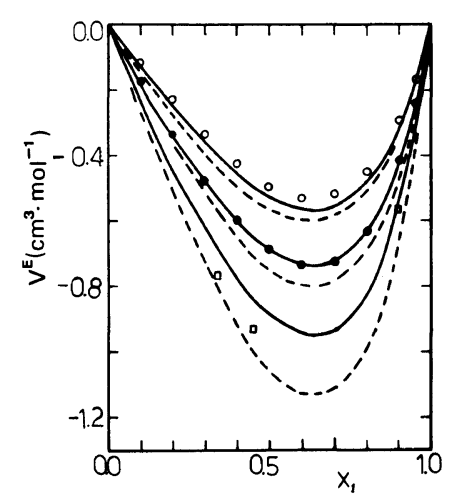

Figure 2. Experimental ${ }^{11}$ and calculated excess volumes for the system $n$-Hexane(1) $+n$-Hedadecane(2). $\bigcirc$, data at $20^{\circ} \mathrm{C} ; 0$, data at $40^{\circ} \mathrm{C} ; \square$, data at $60^{\circ} \mathrm{C}$. — calculated with the present model; ----, calculated with Flory's model. ${ }^{8}$

result of the above mentioned optimization scheme through which only three parameters were kept adjustable $\left(T_{\mathrm{CH}_{3}}^{*}, v_{\mathrm{CH}_{3}}^{*}, r_{\mathrm{CH}_{3}}\right)$. On the basis of these parameters we have calculated the excess volumes for a number of equimolar binary mixtures of $n$-alkanes. Experimental and calculated excess volumes are shown in Table I, where are shown, also, the calculated values with the new Flory theory. ${ }^{8}$ Notice that all equation-of-state parameters in the Flory theory are temperature dependent and, in addition, its binary parameter $X_{12}$ was treated as adjustable. In view of this, the performance of our elementary model is rather satisfactory. In 
Table I. Excess volumes of equimolar $n$-alkane mixtures

\begin{tabular}{|c|c|c|c|c|}
\hline \multirow{3}{*}{ System } & \multirow{3}{*}{$\frac{\text { Temp }}{{ }^{\circ} \mathrm{C}}$} & \multirow{3}{*}{ Experimental } & \multicolumn{2}{|c|}{$V^{\mathrm{E}} / \mathrm{cm}^{3} \mathrm{~mol}^{-1}$} \\
\hline & & & \multicolumn{2}{|c|}{ Calculated } \\
\hline & & & Flory $^{e}$ & $\begin{array}{l}\text { Present } \\
\text { model }\end{array}$ \\
\hline \multirow[t]{3}{*}{$\mathrm{C}_{6}+\mathrm{C}_{12}$} & 20 & $-0.31^{\mathrm{a}}$ & -0.34 & -0.32 \\
\hline & 25 & $-0.35^{\mathrm{b}}$ & -0.37 & -0.35 \\
\hline & 35 & $-0.38^{b}$ & -0.44 & -0.39 \\
\hline \multirow{6}{*}{$\mathrm{C}_{6}+\mathrm{C}_{16}$} & 20 & $-0.49^{\mathrm{a}, \mathrm{c}}$ & -0.56 & -0.53 \\
\hline & 25 & $-0.56^{\mathrm{a}, \mathrm{b}}$ & -0.61 & -0.57 \\
\hline & 30 & $-0.58^{c}$ & -0.65 & -0.61 \\
\hline & 40 & $-0.69^{c}$ & -0.76 & -0.69 \\
\hline & 50 & $-0.82^{\mathrm{c}}$ & -0.89 & -0.78 \\
\hline & 60 & $-0.97^{\mathrm{c}}$ & -1.05 & -0.89 \\
\hline $\mathrm{C}_{6}+\mathrm{C}_{24}$ & 51 & $-1.19^{d}$ & -1.34 & -1.19 \\
\hline \multirow{2}{*}{$\mathrm{C}_{7}+\mathrm{C}_{12}$} & 25 & $-0.17^{b}$ & -0.23 & -0.19 \\
\hline & 35 & $-0.20^{\mathrm{b}}$ & -0.26 & -0.22 \\
\hline \multirow[t]{4}{*}{$\mathrm{C}_{7}+\mathrm{C}_{16}$} & 20 & $-0.31^{\mathrm{a}}$ & -0.40 & -0.35 \\
\hline & 25 & $-0.34^{\mathrm{a}}$ & -0.42 & -0.37 \\
\hline & 40 & $-0.45^{\mathrm{a}}$ & -0.50 & -0.44 \\
\hline & 76 & $-0.77^{d}$ & -0.74 & -0.70 \\
\hline $\mathrm{C}_{7}+\mathrm{C}_{24}$ & 76 & $-1.22^{\mathrm{d}}$ & -1.24 & -1.14 \\
\hline $\mathrm{C}_{7}+\mathrm{C}_{36}$ & 76 & $-1.56^{\mathrm{d}}$ & -1.77 & -1.53 \\
\hline \multirow[t]{5}{*}{$\mathrm{C}_{8}+\mathrm{C}_{16}$} & 20 & $-0.19^{\mathrm{a}}$ & -0.24 & -0.22 \\
\hline & 30 & $-0.21^{\mathrm{a}}$ & -0.27 & -0.25 \\
\hline & 50 & $-0.33^{a}$ & -0.36 & -0.32 \\
\hline & 76 & $-0.48^{d}$ & -0.52 & -0.44 \\
\hline & 106 & $-0.74^{\mathrm{d}}$ & -0.82 & -0.64 \\
\hline $\mathrm{C}_{8}+\mathrm{C}_{24}$ & 106 & $-1.33^{\mathrm{d}}$ & -1.46 & -1.18 \\
\hline $\mathrm{C}_{8}+\mathrm{C}_{32}$ & 96 & $-1.49^{d}$ & -1.61 & -1.36 \\
\hline $\mathrm{C}_{8}+\mathrm{C}_{36}$ & 106 & $-1.85^{\mathrm{d}}$ & -2.07 & -1.65 \\
\hline $\mathrm{C}_{9}+\mathrm{C}_{16}$ & 126 & $-0.61^{d}$ & -0.70 & -0.51 \\
\hline \multirow[t]{2}{*}{$\mathrm{C}_{9}+\mathrm{C}_{24}$} & 76 & $-0.63^{d}$ & -0.62 & -0.61 \\
\hline & 106 & $-0.96^{\mathrm{d}}$ & -1.05 & -0.86 \\
\hline \multirow[t]{2}{*}{$\mathrm{C}_{9}+\mathrm{C}_{36}$} & 96 & $-1.25^{\mathrm{d}}$ & -1.39 & -1.16 \\
\hline & 106 & $-1.41^{\mathrm{d}}$ & -1.59 & -1.30 \\
\hline \multirow[t]{2}{*}{$\mathrm{C}_{9}+\mathrm{C}_{16}$} & 20 & $-0.07^{\mathrm{a}}$ & -0.10 & -0.09 \\
\hline & 30 & $-0.09^{\mathrm{a}}$ & -0.10 & -0.10 \\
\hline
\end{tabular}

${ }^{a}$ Reference 12. b Reference 13. ${ }^{\mathrm{c}}$ Reference 11.

d Reference 10 . e Reference 8.

Figure 2 are shown experimental and calculated $V^{\mathrm{E}}$ for the system $n$-Hexane $+n$ Hexadecane over the complete composition range. The model properly predicts the effect of composition on $V^{\mathrm{E}}$ for this system while the predicted effect of temperature is qualitatively correct. With the same set of characteristic
Table II. Excess enthalpies of equimolar $n$-alkane mixtures

\begin{tabular}{|c|c|c|c|c|}
\hline \multirow{3}{*}{ System } & \multirow{3}{*}{$\frac{\text { Temp }}{{ }^{\circ} \mathrm{C}}$} & \multirow{3}{*}{ Experimental } & \multicolumn{2}{|c|}{$H^{\mathrm{E}} / \mathrm{cal} \mathrm{mol}^{-1}$} \\
\hline & & & \multicolumn{2}{|c|}{ Calculated } \\
\hline & & & Flory $^{\mathrm{h}}$ & $\begin{array}{c}\text { Present } \\
\text { model }\end{array}$ \\
\hline $\mathrm{C}_{6}+\mathrm{C}_{10}$ & 20 & $4^{a}$ & 7 & 7 \\
\hline $\mathrm{C}_{6}+\mathrm{C}_{12}$ & 20 & $11^{b, c}$ & 12 & 12 \\
\hline \multirow[t]{5}{*}{$\mathrm{C}_{6}+\mathrm{C}_{16}$} & 20 & $31^{\mathrm{d}}$ & 23 & 22 \\
\hline & 30 & $23^{d}$ & 21 & 21 \\
\hline & 40 & $16^{e}$ & 19 & 19 \\
\hline & 50 & $8^{d}$ & 16 & 17 \\
\hline & 60 & $4^{e}$ & 13 & 14 \\
\hline \multirow{3}{*}{$\mathrm{C}_{6}+\mathrm{C}_{24}$} & 51 & $33^{\mathrm{e}}$ & 31 & 30 \\
\hline & 60 & $22^{\mathrm{e}}$ & 27 & 26 \\
\hline & 76 & $6^{e}$ & 19 & 20 \\
\hline \multirow[t]{3}{*}{$\mathrm{C}_{7}+\mathrm{C}_{16}$} & 20 & $26^{\mathrm{a}}$ & 16 & 16 \\
\hline & 25 & $23^{\mathrm{f}}$ & 16 & 15 \\
\hline & 50 & $10^{\mathrm{f}}$ & 13 & 12 \\
\hline $\mathrm{C}_{7}+\mathrm{C}_{36}$ & 76 & $31^{\mathrm{e}}$ & 35 & 27 \\
\hline $\mathrm{C}_{8}+\mathrm{C}_{16}$ & 20 & $21^{\mathrm{a}}$ & 12 & 11 \\
\hline \multirow[t]{4}{*}{$\mathrm{C}_{8}+\mathrm{C}_{24}$} & 51 & $28^{\mathrm{e}}$ & 21 & 19 \\
\hline & 76 & $10^{\mathrm{e}}$ & 16 & 14 \\
\hline & 96 & $-1^{e}$ & 11 & 9 \\
\hline & 106 & $-6^{e}$ & 8 & 6 \\
\hline $\mathrm{C}_{8}+\mathrm{C}_{32}$ & 76 & $23^{e}$ & 24 & 21 \\
\hline $\mathrm{C}_{9}+\mathrm{C}_{36}$ & 76 & $29^{\mathrm{e}}$ & 26 & 20 \\
\hline \multirow[t]{3}{*}{$\mathrm{C}_{10}+\mathrm{C}_{16}$} & 20 & $12,{ }^{\mathrm{a}} 10^{\mathrm{g}}$ & 5 & 5 \\
\hline & 30 & $8^{g}$ & 5 & 5 \\
\hline & 73 & $4^{\mathrm{g}}$ & 4 & 3 \\
\hline $\mathrm{C}_{16}+\mathrm{C}_{36}$ & 76 & $14^{e}$ & 9 & 7 \\
\hline
\end{tabular}

parameters we have calculated the excess enthalpies of a number of equimolar binary mixtures, of normal paraffins. Experimental and calculated $H^{\mathrm{E}}$ with, both, the Flory theory ${ }^{8}$ and the present model are shown in Table II. Once again the performance of the LF group contribution model is satisfactory and comparable with the Flory's model which uses many more adjustable parameters. The comments made previously concerning the predictions for the effect of composition and temperature on $V^{\mathrm{E}}$ are valid for the $H^{\mathrm{E}}$ also. 


\section{DISCUSSION}

The development of the group contribution model in this work is in conformity with Brönsted's principle of congruence. ${ }^{9,10}$ According to this principle, a property of the mixture of components 1 and 2 such as the molar volume or the molar enthalpy should equal that for the intermediate homolog for which $N_{\mathrm{c}}=\sum_{\mathrm{i}} x_{\mathrm{i}} N_{\mathrm{ci}}, N_{\mathrm{c}}$ being the number of carbon atoms in the molecule. In fact the present approach goes beyond the principle of congruence as it may predict not only the properties of the mixtures from the properties of their pure components but, also, the properties of the pure components at any (in principle) external conditions. It must be noticed that in the present treatment we have not given emphasis on the mere agreement between experimental and calculated values but rather, on the development of a most simple and consistent group contribution model which is at least as good as similar models in the literature and which may, certainly, form the basis for more refined treatments. All calculations in this work have been made by treating as adjustable parameters, only the three scaling constants of group $-\mathrm{CH}_{3}$ and, to a lesser extend, the characteristic molecular parameter $S_{\mathrm{CH}_{2}} / S_{\mathrm{CH}_{3}}$. Adjustment of the corresponding parameters for group $-\mathrm{CH}_{2}-$ and use of an overall optimization scheme would, certainly, improve the performance of the model.

The present model has, of course, all basic drawbacks of the molecular Lattice-Fluid theory. ${ }^{2-5}$ The later is an approximate model of the fluid state. As with all similar models, the set of the characteristic scaling constants for a pure compound depends strongly on the property(ies) which has been used in the data reduction for the estimation of these constants. In this work we have used only volumetric properties for $n$-alkane liquids and high polyethylenes for the estimation of the scaling constants for groups $-\mathrm{CH}_{3}$ and $-\mathrm{CH}_{2}-$. The comparison, thus, with the new Flory theory has been made, in this respect, on an equal basis. However, the LF theory predicts vaporliquid transition and, thus, other thermophysical properties such as vapor pressures, heats of vaporization and orthobaric densities may, also, be used for the estimation of the scaling constants. Evaluations of the chemical potentials or the activity coefficients are more appropriately done with scaling constants obtained from these later properties than the volumetric properties. ${ }^{2-5}$ Work along these lines, but mainly oriented to small molecules, is underway in our Laboratory.

Acknowledgements. The author is thankful to the General Secretariat of Research and Technology of Greece for financial support.

\section{REFERENCES}

1. C. Panayiotou, Makromol. Chem., 188, 2733 (1987).

2. C. Panayiotou, Makromol. Chem., 187, 2867 (1986)

3. C. Panayiotou, Macromolecules, 20, 861 (1987).

4. C. Panayiotou, J. Phys. Chem., in press.

5. I. C. Sanchez and R. H. Lacombe, Macromolecules, 11, 1145 (1978).

6. P. J. Flory, R. A. Orwoll, and A. Vrij, J. Am. Chem. Soc., 86, 3507 (1964).

7. R. A. Orwoll and P. J. Flory, J. Am. Chem. Soc., 89, 6814 (1967).

8. R. A. Orwoll and P. J. Flory, J. Am. Chem. Soc., 89, 6822 (1967).

9. J. N. Bronsted and J. Koefoed, Kgl. Danske Videnskab. Selskab, Mat.-Fys. Medd., 22, 1 (1946).

10. Th. Holemann, Physica, 29, 585 (1963).

11. M. Diaz Pena and M. Benitez de Soto, Anales Real Soc. Espan. Fis. Quim. (Madrid), Ser. B, 61, 1163 (1965).

12. A. Desmyter and J. H. van der Waals, Rec. Trav. Chim., 77, 53 (1958).

13. J. D. Gomez-Ibanez and C.-T. Liu, J. Phys. Chem., 67, 1388 (1963).

14. M. L. McGlashan and K. W. Morcom, Trans. Faraday Soc., 57, 907 (1961).

15. J. H. van der Waals, Rec. Trav. Chim., 70, 101 (1951).

16. H. F. Stoeckli, J. G. Fernandez-Garcia, and C. G Boissonnas, Trans. Faraday Soc., 62, 3044 (1966).

17. M. L. McGlashan and K. W. Morcom, Trans. Faraday Soc., 57, 581 (1961).

18. Th. Holeman, Physica, 31, 49 (1965).

19. G. W. Lundberg, J. Chem. Eng. Data, 9, 193 (1964).

20. J. H. van der Waals and J. J. Hermans, Rec. Trav. Chim., 69, 949 (1950). 